\title{
Performance: maatstaven, systemen en management
}

\section{Cees van Halem}

SAMENVATTING In dit artikel wordt ingegaan op drie onderling samenhangende vraagstukken betreffende het meten van de performance van organisaties. Het eerste betreft het specificeren van de prestatiemaatstaven. Hoe kan de organisatie performancedriven worden gestuurd? Om deze vraag te beantwoorden wordt ingegaan op het organisatorische aspect, in casu het ontwikkelen van procedures en systemen (tweede vraagstuk); en op het gedragsmatige aspect, in casu het realiseren en onderhouden van een zodanige 'mind set' bij alle organisatieleden, dat hun dagelijks handelen wordt gericht op het realiseren van de doelstellingen van de organisatie (derde vraagstuk).

\section{Inleiding}

Om redenen van levensvatbaarheid, continuïteit en maatschappelijke verantwoordelijkheid zijn organisaties gericht op het realiseren van 'bijdrage(n)' aan de verwezenlijking van door hen gestelde, dan wel aan hen opgelegde doelstellingen. Het management van organisaties is de belangrijkste verantwoordelijke voor het beheersen van de operaties op een zodanige wijze dat deze bijdrage(n) ook daadwerkelijk wordt c.q. worden gerealiseerd: het management wordt 'afgerekend' op de 'over all performance' van de organisatie, op haar beurt zal het management de organisatie in al haar onderdelen zodanig sturen dat de gestelde of noodzakelijk geachte performance wordt bereikt.

De beheersing ('control') van de operaties vooronderstelt dat de performance van de operaties, gespecificeerd naar bedrijfsonderdelen, bedrijfsfuncties en

Prof. Dr. C. van Halem is directeur van Oasis BV. Daarnaast is hij parttime hoogleraar Management Accounting \& Control aan de Erasmus Universiteit te Rotterdam, specifiek voor de postdoctorale Controllersopleiding. wellicht zelfs functionarissen, kan worden uitgedrukt in één of meer maatstaven. Maatstaven die een nauwe band onderhouden met de doelstellingen van de organisatie. Het specificeren van deze maatstaven is in de praktijk een weerbarstig vraagstuk dat slechts per geval met de nodige creativiteit kan worden opgelost. Indien er al duidelijkheid bestaat over de maatstaven waardoor performance kan worden afgebeeld, doemt wellicht een nog groter vraagstuk op, namelijk: hoe kan de organisatie performancegedreven worden gestuurd. In termen van de gebruikelijke terminologie: hoe kan performance management in de praktijk concreet vorm krijgen. Hiervoor zijn inspanningen nodig van organisatorische en gedragsmatige aard.

De organisatorische component betreft procedures en systemen. Procedures in de vorm van bijvoorbeeld planning-en controlcycli en systemen die de gegevens die performance afbeelden, bewaren, bewerken en distribueren. Het gedragsmatige aspect betreft het realiseren en onderhouden van een zodanige 'mind set' bij alle organisatieleden, dat hun dagelijks handelen performancegedreven wordt; anders gezegd: gericht wordt op het realiseren van de doelstellingen van de organisatie.

In dit artikel zullen wij ingaan op een drietal, onderling samenhangende aspecten van het thema performance. Achtereenvolgens gaat de aandacht uit naar de volgende vragen:

a hoe kunnen de doelstellingen van de organisatie worden afgebeeld in maatstaven voor performance;

b hoe wordt de kwantitatieve weergave van deze grootheden ('de meetresultaten') bewaard, bewerkt en gedistribueerd, rekening houdend met de stand van de administratieve techniek anno 2002 (lees: de toepassing van informatie- en communicatietechnologie);

c hoe kan performance management concreet inhoud krijgen in de vorm van de feitelijke sturing van de organisatie. 
De behandeling van deze vragen zal worden afgesloten met een korte reflectie op het meest prominente onderdeel van de huidige praktijk van performance management, te weten de budgetteringspraktijk. Naar zal blijken verdient deze praktijk een revitaliseringsslag. Hopelijk zal de lezer in het onderstaande daartoe nuttige bouwstenen vinden.

\section{De doelstellingen van de organisatie afgebeeld in maatstaven voor performance}

Rondom het thema performance komt als eerste vraag naar voren: in welke maatstaf of maatstaven wordt performance uitgedrukt: hoe kan performance worden afgebeeld? In de context van 'not-for-profit'organisaties leidt deze vraag al snel tot breedlopende discussies. De belangriikste oorzaak daarvan is gelegen in het feit dat in die gevallen de doelstellingen (groten)deels niet meetbaar zijn en daarnaast ook niet zelden onderling concurrerend zijn.

De vraag lijkt gemakkelijker te beantwoorden in naar winst strevende organisaties. Financiële prestaties lijken dan de natuurlijke maatstaf te zijn voor de uitdrukking van de performance. Als blijk daarvan kan worden verwezen naar veel bonusregelingen die op winst zijn gestoeld.

Men kan zich echter afvragen of winst wel een goede uitdrukking is van de bijdrage aan de strategische doelstellingen. Vragen die in dat kader opkomen zijn:

- Is de jaarwinst over de afgelopen periode wel een goede uitdrukking van 'levensvatbaarheid', continuïteit, winst op lange termijn, maximalisatie van de aandeelhouderwaarde, of welke (financiële) strategische doelstelling dan ook? Gaat het niet veeleer om de toekomstige winsten: dat zijn toch immers de grootheden die iets zeggen over de doelstellingen of strategische ambities zoals hierboven verwoord?

- Is jaarwinst als retrospectief bepaalde grootheid wel een goede indicator; moeten we bij de beoordeling van de performance over de afgelopen periode niet veeleer kijken naar de ontwikkeling van factoren die de winst bepalen, de zogenaamde 'drivers'? Een teruglopende klantentrouw zal qua effect nog niet merkbaar zijn in de winst van deze periode, maar zal zeker haar gevolgen hebben in de perioden die volgen.

Bovenstaande overwegingen hebben ertoe geleid dat de term performance in de laatste jaren in een nieuw daglicht is gekomen. Kort gezegd komen de huidige inzichten hierop neer dat 'performance' in elk specifiek geval concreet inhoud moet krijgen, dat wil zeggen: (vanzelfsprekend) organisatiespecifiek, maar daarnaast ook specifiek voor elk managementniveau en periodespecifiek. Daarbij geldt dat winst als retrospectief bepaalde grootheid slechts van geringe betekenis is als het gaat over de toekomstige vitaliteit van de organisatie, en verder dat de factoren die tot performance leiden, vanuit de optiek van management control in feite aandacht verdienen, meer dan het daaruit voortvloeiende resultaat. Mutatis mutandis gelden dezelfde overwegingen voor niet naar winst strevende organisaties; ook daar zal - uitgaande van maatschappelijke doelstellingen - moeten worden bepaald wat de 'drivers' zijn die leiden tot het hoger gestelde doel, gespecificeerd naar organisatieonderdeel, functie en mogelijk zelfs functionaris.

Het begrip performance heeft met name de laatste jaren een meerdimensionele betekenis gekregen door de publicaties van Kaplan en Norton (1992, 1993, 1996) in de vorm van de door hen geïntroduceerde Business Balanced Scorecard (BBSc). Hun betoog komt kort gezegd hierop neer dat performance langs een aantal assen moet worden gemeten; niet alleen de financiële as, maar ook langs assen als 'markt', 'interne processen' en 'innovatie'. Niet dat deze factoren op zichzelf nastrevenswaardig zouden zijn en in de plaats zouden komen van de vigerende strategische ambitie (in naar winststrevende organisaties gemakshalve gedefinieerd als: maximalisatie van de winst op lange termijn), maar veeleer om te benadrukken dat deze factoren 'drivers' zijn achter het uiteindelijke financiële resultaat. In de visie van Kaplan en Norton moet performance (gemeten langs elke genoemde as) worden uitgedrukt in een aantal kwantitatieve performance-indicatoren. Deze indicatoren hebben als eigenschap dat zij - direct of indirect - een bepalende factor ('driver') zijn bij het realiseren van de uiteindelijke doelstelling van de organisatie.

Performance kan worden uitgedrukt in een (onderling samenhangende) verzameling van factoren of indicatoren. Performance is dan een multidimensionele grootheid geworden. De maatstaf waarin performance wordt uitgedrukt, is derhalve niet langer ééndimensionaal in termen van een winst- of kostenverschil. Hierdoor is ook de jaarbegroting multidimensionaal geworden, aangezien niet langer uitsluitend in financiële termen wordt begroot, maar ook de onderliggende niet-financiële drivers (in samenhang met het begrote financiële resultaat) worden 'begroot'.

\section{Beheer en distributie van performance- \\ indicatoren (de organisatie van de management-informatieverzorging)}

In dit onderdeel gaat het om de vraag hoe de kwantitatieve weergave van performance ('de indicatoren') 
kunnen worden bewaard, bewerkt en gedistribueerd. Bepaling van de maatstaven moge dan de basis van alles zijn, de betekenis hiervan voor de organisatie staat of valt bij de vaardigheid om te komen tot de ontwikkeling en implementatie van een systeem dat de vergaarde gegevens kan bewaren, bewerken, distribueren en representeren.

Hierbij moet het begrip systeem worden opgevat in termen van definities, procedures, hardware en software. Wetenschappers op het terrein van Management Accounting \& Control lijken over het algemeen voor dit aspect van performance weinig belangstelling te kunnen opbrengen. Daar staat tegenover dat 'de praktijk' bijna uitsluitend met dit aspect van performance bezig is. In feite liggen de accenten als volgt:

- De wetenschappelijke visie op het thema performance management is sterk gericht op de definitie van maatstaven als afbeelding van performance.

- De praktijk rondom het thema performance is bijna uitsluitend bezig met een versmalling van het thema tot de softwaretechnische kant van informatieverzorging.

In dit onderdeel gaan wij apart in op de 'organisatie van de informatieverzorging'; in aanvulling op hetgeen hiervoor is gesteld over de maatstaven, en in aanvulling op 'de praktijk' die zich sterk concentreert op het ontwerp van procedures en de keuze van het software-instrumentarium. Hierbij zullen wij niet voorbij gaan aan het gegeven dat informatieverzorging en de toepassing van informatie- en communicatietechnologie heden ten dage onlosmakelijk met elkaar zijn verbonden.

Strikt genomen is het van ondergeschikt belang of bij de management-informatieverzorging informatietechnologie wordt ingezet. Om redenen van snelheid, actualiteit en minimalisatie van distributiekosten worden echter in toenemende mate elektronische middelen ingezet om de managementrapportage te verzorgen. In feite gaat het daarbij om de toepassing van software die gegevens uit onderliggende (elektronische) dataverzamelingen toegankelijk maakt. Soms vindt rapportage direct vanuit de basisregistratie plaats; vaak wordt echter een aparte dataverzameling opgebouwd ten behoeve van managementrapportagedoeleinden. Een dergelijke specifieke dataverzameling ('datawarehouse') is in feite een kopie van de voor managementrapportage relevant geachte gegevens uit diverse basisregistraties. Het voordeel van een dergelijke structuur is dat de systemen voor basisregistratie niet voortdurend worden belast met vragen betreffende managementinformatie; slechts periodiek (bijvoorbeeld elk etmaal) worden de gegevens in het datawarehouse ververst. Daarnaast geldt als voordeel van een datawarehouse dat veelal een groter historisch bereik kan worden geraadpleegd dan mogelijk zou zijn indien direct vanuit de bronbestanden zou moeten worden 'getapt'.

Het datawarehouse is in feite het bronbestand voor het management dashboard in de vorm van een balanced scorecard. Daarnaast is het datawarehouse van belang voor analisten en stafmedewerkers vanwege de beschikbaarheid van onderliggende data. Dankzij deze data kunnen deze kenniswerkers het management van extra informatie voorzien; al dan niet als resultaat van vragen die het management heeft naar aanleiding van de 'reguliere rapportage'. De inzet van elektronische hulpmiddelen is van wezenlijke betekenis voor de kwaliteit van management control. Immers, dankzij de hierdoor verschafte mogelijkheden is steeds een rapportage mogelijk die ook actueel is. Ook kan ICT een bijdrage leveren aan de consistentie. Natuurlijk is de grondslag van consistentie het hanteren van eenduidige definities; daar kan ICT niets aan bijdragen. Wel is ICT van nut als het gaat om het verschaffen van een rapportagestructuur waarbij uit dezelfde dataverzamelingen wordt gerapporteerd, zodat consistentie - uitgaande van een consistente begrippenstructuur - gewaarborgd wordt en dat elke manager over dezelfde gegevens beschikt. Anders gezegd: dankzij ICT heeft 'iedereen, dezelfde informatie, op hetzelfde tijdstip'; consistentie van begrippen is daarbij een voorwaarde.

\section{Management van performance}

Indien eenduidig vaststaat welke grootheden de performance afbeelden en een systeem van managementrapportage is geïmplementeerd dat alle betrokkenen tijdig de relevante informatie verschaft, blijft er nog een beslissende schakel over die het succes van de gehele keten bepaalt: het management van performance. De finale schakel in de vorm van performance management betreft in feite het creëren en onderhouden van een 'mindset' van de organisatie in al haar onderdelen. Het gaat om een instelling, een manier van denken en sturen die zich in de eerste plaats van het management zelf meester moet maken, maar daarna ook - mede als resultaat daarvan - van de onderliggende niveaus.

Dit betekent concreet dat de lagere managementechelons zich aan de grondslagen committeren die achter de criteria schuilgaan, c.q. de 'doorvertaling' van de strategische ambitie naar concrete 'value drivers' accepteren, ondersteunen en tot hun 'geestelijk eigendom' hebben gemaakt. 
In de praktijk liggen hier vaak de voornaamste problemen. Hierbij kan men aan het volgende denken:

$1 \mathrm{Bij}$ de vaststelling van de inhoud van het begrip performance, de maatstaven waarin dit begrip wordt uitgedrukt, heeft het topmanagement zich idealiter laten leiden door haar strategische ambities. Het probleem dat opdoemt is evenwel: hoe worden deze strategische ambities 'doorvertaald' in concrete ambities (lees: indicatoren en targets) op de verschillende deelterreinen waarvoor de lagere managementechelons verantwoordelijk zijn. Anders gezegd: het topmanagement kan op basis van de gestelde ambities volgens de regelen der kunst tot een set van Kern Prestatie Indicatoren (KPI) komen; strikt genomen zijn deze grootheden alleen richtinggevend voor de 'over all performance', ofwel: de performance van het topmanagement. Elk van deze grootheden zal moeten worden doorvertaald - of zo men wil: nader moeten worden gespecificeerd - voor het deelbereik waarvoor het tweede echelon verantwoordelijk is. Om dit goed te kunnen realiseren is in feite een vertaalslag nodig met als hoofdvraag: hoe kunnen de door het topmanagement gestelde doelstellingen worden gerealiseerd voorzover dit het lager gelegen verantwoordelijkheidsbereik betreft. In onze beleving ontbreekt een dergelijke nadere specificering nogal eens in de praktijk. Niet zelden worden de door de topleiding gevonden criteria simpelweg aan het lagere echelon opgelegd, zonder dat een concrete doorvertaling naar hun verantwoordelijkheidsgebied is gemaakt. Bij die

Een belangrijk hulpmiddel bij de doorvertaling van 'over all performance'-indicatoren naar indicatoren op lager gelegen echelons, is de methodiek van Mental of Cognitive Mapping. Deze uit de psychologie afkomstige methodiek geniet tegenwoordig veel belangstelling van bedrijfskundigen, vooral als resultaat van het werk van Eden (1989). Onder leiding van een facilitator wordt de groep probleemhebbers de vraag voorgelegd welke indicatoren naar hun individueel inzicht een nadere specificatie, c.q. doorvertaling zouden kunnen zijn. De antwoorden worden op stickers geschreven en verzameld om in een plenaire sessie te worden besproken. Bij die gelegenheid zal al snel blijken dat een aantal probleemhebbers dezelfde indicatoren noemen, zij het met een verschillende aanduiding. Verder zal zich snel een hiërarchisch patroon in de genoemde indicatoren aftekenen. Dit laatste is vervolgens het uitgangspunt om tot een verbijzondering van de 'over all indicatoren' te komen en wel op een zodanige wijze dat per niveau van verantwoordelijkheid, zinvolle maatstaven kunnen worden geïdentificeerd. Zie hiertoe Van Halem en Heuvelmans (1999) en de daar genoemde literatuurverwijzingen. doorvertaling moet duidelijk worden welke 'drivers' op het lager gelegen niveau zullen leiden tot de door het topmanagement gestelde indicatoren en hun targets. Het logisch verbinden van sets van indicatoren/targets, onderling en met de strategische ambitie van de gehele organisatie via een zogenaamde 'strategy map, is van het grootste belang om tot een gedeeld inzicht te komen van de anatomie en de werking van de organisatie (Kaplan en Norton, 2000). Een dergelijk gedeeld inzicht kan worden bereikt als het submanagement de door het topmanagement gestelde ambities als datum accepteert en in de gelegenheid wordt gesteld om de consequenties voor het eigen handelen daarvan 'door te redeneren'.

2 In nauwe samenhang met het voorgaande punt: het is ronduit ineffectief indien de organisatie (lees: het topmanagement) besluit om performance voortaan multidimensionaal te definiëren en te meten, als vervolgens de aloude bonusstructuur in stand wordt gehouden; kort gezegd: hoe meer winst hoe hoger de bonus. Als een dergelijke simpele regel valide blijft, zal de mindset niet veranderen. In de praktijk waarin performance management binnen organisaties aan de orde komt (al dan niet uitgewerkt tot balanced scorecards en datawarehouses) zien we bijna altijd dat de 'introductie' tot de top wordt beperkt. Doorvertaling van de nieuwe targets naar lager gelegen managementniveaus wordt niet uitgevoerd; laat staan dat de interne beloningsstructuur wordt aangepast. Als gevolg van deze nalatigheid zullen alle voorafgaande inspanningen in de vorm van de definitie van performance, de maatstaf waarin dat wordt uitgedrukt en het beheren en distribueren van data over performance-indicatoren in de vorm van een management informatiesysteem, tot nagenoeg zinloze acties degraderen; het uiteindelijke effect is immers nagenoeg nihil indien de handelingen in de organisatie niet conform verlopen.

\section{De budgettering voorbij?}

Nog te vaak wordt het proces van budgetteren en budgetanalyse als het hart van performance management beschouwd. Uit het voorgaande moge duidelijk geworden zijn dat budgettering in de klassieke betekenis van het woord onvoldoende is, zeker indien dit met name gericht is op de financiële component van de bedrijfsgang. In feite zijn er twee bezwaren tegen deze gang van zaken:

- de budgettering is vaak onvoldoende ingebed in de strategische langetermijnambities;

- de budgettering is ééndimensionaal. 
Budgettering is niet zelden een jaarlijks terugkerend 'ritueel' dat sterk leunt op de performance van het afgelopen jaar. Alle 'belijdenissen' ten spijt; de strategische langetermijnambities blijven bij de jaarlijkse budgetteringsronde vaak vaag en amorf op de achtergrond. Tegen de achtergrond hiervan kan men zich in rede afvragen: wat is het nut van de jaarlijkse budgetteringsronde? Natuurlijk zijn er vele voordelen: de hele organisatie wordt gedwongen om zich op de nabije toekomst te bezinnen (zij het voornamelijk in financiële termen), afstemming en coördinatie tussen bedrijfsonderdelen is noodzakelijk (en dat is een groot goed), maar wat brengt het ons echt als het perspectief van een geaccordeerde begroting niet veel meer is dan een strikt financieel kompas, onvoldoende duidelijk ingebed in de strategische koers, dat bovendien na enkele maanden als een financiële achteruitkijkspiegel functioneert, tegen een omgevingsachtergrond die intussen allang is veranderd. De belangrijkste tegenwerping zal niet zelden zijn: we doen het al zo lang, en we hebben niets anders. Toegegeven: 'gooi nooit oude schoenen weg voordat je nieuwe hebt'; dat geldt ook hier. Echter, er zijn nieuwe mogelijkheden, zoals uit het bovenstaande moge blijken.

De budgettering is ééndimensionaal. Dit bezwaar is in het voorafgaande uitvoerig voor het voetlicht gekomen. Planning en control van organisaties is wellicht te lang het domein geweest van financieeleconomisch geschoolden; daardoor is budgettering niet zelden verworden tot een vorm van gecoördineerde financiële forecasting onder regie van de financiële functie binnen het bedrijf. Het is de hoogste tijd om deze hegemonie te verbreken en middelen en structuren te vinden waarin 'het kijken naar de toekomst' en het vertalen daarvan naar concrete handvatten op de werkvloer, werkelijkheid kan worden.

\section{Samenvatting en conclusie}

Drie onderling samenhangende aspecten van het thema performance, de performancemaatstaven, de systemen en het management van de performance, zijn in dit artikel aan de orde geweest. Performance wordt uitgedrukt in een onderling samenhangende verzameling factoren of indicatoren, waardoor performance een multidimensionale grootheid wordt. ICT is van belang bij het verschaffen van een rapportagestructuur waarbij uit dezelfde dataverzamelingen (datawarehouses) wordt gerapporteerd. Het management van de performance betreft het creëren en onderhouden van een 'mindset' van de organisatie in al haar onderdelen. Sets van indicatoren/targets die logisch verboden zijn, zowel onderling als met de strategie van de gehele organisatie, in de vorm van een 'strategy map', zijn essentieel voor deze 'mindset'. Op deze wijze vindt doorvertaling plaats van 'over all performance'-indicatoren naar indicatoren op lager gelegen echelons. De traditionele budgettering blijkt niet meer te voldoen omdat hierin alleen aandacht is voor de financiële component (ééndimensionaal) en omdat deze vaak onvoldoende is ingebed in de langetermijnstrategie van de organisatie.

\footnotetext{
Literatuur

Checkland, P. en J. Scholes, (1990), Soft Systems Methodology in Action Wiley, Chichester.

Eden, C., (1989), Using Cognitive Mapping for Strategic Options Development and Analysis (SODA), in: Rational Analysis for a Problematic World, J. Rosenhead (ed), Wiley, Chichester.

Halem, C. van en H.G.M. Heuvelmans, (1999), Strategic Control, in: Tijdschrift Financieel Management, Jaargang 19, 1, pp. 51-62.

Hodgson, A.M., (1992), Hexagons for System Thinking, Elsevier Science Publishers.

Johnson, H.T. en R.S. Kaplan, (1987), Relevance Lost: The Rise and Fall of Management Accounting, Harvard Business School Press, Boston.

Kaplan, R.S. en D.P. Norton, (1992), The Balanced Scorecard Measures That Drive Performance, in: Harvard Business Review, 1, pp. 71-79.

Kaplan, R.S. en D.P. Norton, (1993), Putting the Balanced Scorecard to Work, in: Harvard Business Review, 5, pp. 134-142.

Kaplan, R.S. en D.P. Norton, (1996), Using the Balanced Scorecard as a Strategic Management System, in: Harvard Business Review, 1, pp. 75-85. Kaplan, R.S. en D.P. Norton, (2000), Having Trouble with your Strategy? Then map it, in: Harvard Business Review, 5, pp. 167-176.

Kaplan, R.S. en D.P. Norton, (2001), Building a Strategy-Focussed Organization, in: IVEY Business Journal, May/June, pp.12-19.

Kuys, G., (2001), Door de wolken loopt geen pad: Balanced Scorecard en Informatie Architectuur, in: Management \& Informatie, 4.

Simons, S., (1995), Control in an Age of Empowerment, in: Harvard Business Review, 2, pp. 80-88.

Veen-Dirks, P.M.G. van en M.F.C.M. Wijn, (2000), Kritieke Succesfactoren en de Balanced Scorecard, in: Bedrijfskunde, Jaargang 72, 3.
}

\section{Websites}

De volgende websites zullen de lezer wellicht van dienst zijn bij een verdere oriëntatie op het onderwerp:

www.p-management.com

www.businessfinancemag.com

www.better.management.com

www.ink.nl

www.efqm.org

www.balanced-scorecard.nl 